\title{
Corrigendum
}

\section{Barriers to Physical Activity In Individuals with Spinal Cord Injury: A Western Australian Study - Corrigendum}

Terri Roberton, Romola S. Bucks, Timothy C. Skinner, Gary T. Allison, and Sarah A. Dunlop

doi: http://dx.doi.org/10.1375/jrc.17.2.74, Published by Australian Academic Press

On page 74 the author affiliations should be as follows:

Terri Roberton ${ }^{1}$, Romola S. Bucks ${ }^{1}$, Timothy C. Skinner ${ }^{2}$, Gary T. Allison ${ }^{3}$, and Sarah A. Dunlop ${ }^{1}$

${ }^{1}$ The University of Western Australia

${ }^{2}$ University of Tasmania, Australia

${ }^{3}$ Curtin Health Innovation Research Institute, Australia 